\title{
Produção de biomassa aérea, teor e rendimento de extrato das folhas de crajiru [Arrabidaea chica (Bonpl.) B. Verl.] em função de adubação orgânica em Manaus, estado do Amazonas, Brasil.
}

BRITO, A. U.'; CHAVES, F. C. M. ${ }^{2}$; OKA, J. M.'; AZEVEDO, M. M. B. ${ }^{3 ;}$ BATISTA, A. C'

Universidade Federal do Amazonas, Av. Gal. Rodrigo Otávio Jordão Ramos, 3000, Manaus/AM, CEP: 69077-000.

${ }_{2}^{2}$ Pesquisador Embrapa Amazônia Ocidental, Rodovia AM-010, Km 29, Zona Rural, Manaus/AM, CEP: 69010-

970. ${ }^{3}$ Universidade Federal do Rio de Janeiro, Cidade Universitária - UFRJ, Rio de Janeiro/RJ, CEP:21.941-

630. *Autor para correspondência: celio.chaves@embrapa.br

\begin{abstract}
RESUMO: A espécie Arrabidaea chica pertencente à família Bignoniaceae é também conhecida popularmente como crajiru. É Utilizada tradicionalmente no tratamento de enfermidades da pele, inflamações, infecções, dentre outros. O objetivo deste trabalho foi avaliar a produção de biomassa aérea, teor e rendimento de extrato de crajiru em função de diferentes fontes de adubo orgânico em Manaus, AM. As mudas foram formadas através de estacas e mantidas por 60 dias em casa de vegetação. O experimento foi conduzido em esquema fatorial $5 \times 3 \mathrm{com}$ delineamento em blocos casualizados onde os níveis dos fatores foram as diferentes fontes de adubo orgânico: composto $\left(5,0 \mathrm{~kg} / \mathrm{m}^{2}\right)$, esterco de aves $\left(3,0 \mathrm{~kg} / \mathrm{m}^{2}\right)$, casca de guaraná $\left(4,0 \mathrm{~kg} / \mathrm{m}^{2}\right)$, esterco de gado $\left(4,0 \mathrm{~kg} / \mathrm{m}^{2}\right)$ e controle (ausência), e os três morfotipos de crajiru. Obedeceu-se o espaçamento de 1,0x1,0 m entre planta e 2,0 m entre blocos. Após 240 dias foram avaliadas a produção de folhas e caules, relação folha/caule, teor de extratos hexânico concentrado em evaporador rotativo obtido pela fórmula: (massa do extrato/massa da amostra total)x100; e o rendimento de extrato estimado pela equação: (\%extrato x massa seca total das folhas)/100. Os dados foram submetidos à análise de variância e as médias ao Teste de Tukey $(p<0,05)$. As fontes de adubo orgânico promoveram melhor desenvolvimento das plantas de, exceto para o morfotipo 1. O esterco de aves proporcionou maior produção de biomassa, teor e rendimento de extratos. Dessa forma, sugere-se que a adubação orgânica propicia maior produção de biomassa, teor e rendimento de extratos de $A$. chica.
\end{abstract}

Palavras-chave: Bignoniaceae, adubos orgânicos, plantas medicinais, produção vegetal

\begin{abstract}
Aerial biomass production, content and yield of crajiru leaf extract [Arrabidaea chica (Bonpl.) B. Verl.] as a function of organic fertilizer in Manaus, state of Amazonas, Brazil. The Arrabidaea chica species belongs to the Bignoniaceae family and is also popularly known as crajiru. It is traditionally used to treat skin diseases, inflammations and infections. The objective of this study was to evaluate the biomass production, the content and the yield of crajiru extract in face of different sources of organic fertilizer in Manaus, AM. The seedlings were formed by cuttings and kept for 60 days in a greenhouse. The trial was conducted in a $5 \times 3$ factorial design with randomized block organization where the factor levels were different sources of organic fertilizer: compound $(5.0 \mathrm{~kg} / \mathrm{m} \mathrm{2})$, chicken manure $(3.0 \mathrm{~kg} /$ $\mathrm{m} 2)$, bark guarana $(4.0 \mathrm{~kg} / \mathrm{m} 2)$, cattle manure $(4.0 \mathrm{~kg} / \mathrm{m} \mathrm{2})$ and control (absence), and the three morphotypes of crajiru. It was obeyed the spacing between the plants $(1,0 \times 1,0 \mathrm{~m})$ and the blocks $(2,0 \mathrm{~m})$. After 240 days it were evaluated the production of leaves and stems, the leaf / stem ratio, and the content of hexane extracts concentrated by rotary evaporation obtained by the following formula: (mass of extract / mass of total sample) x100; and the yield estimated by the equation extract: (\% extract $x$ total dry mass of leaves) / 100. The data were subjected to analysis of variance and means to the Tukey's test $(p<0.05)$. The sources of organic fertilizer promoted better development of plants, except for the morphotype 1 . The poultry manure provided higher biomass, content and yield of extracts. Thus, it is suggested that the organic fertilizer provides greater biomass production, content and yield of A. chica extracts.
\end{abstract}

Keywords: Bignoniaceae, organic fertilizers, medicinal plants, crop production

Recebido para publicação em 17/10/2012

Aceito para publicação em 14/08/2014

10.1590/1983-084X/12_123

Rev. Bras. PI. Med., Campinas, v.17, n.3, p.444-453, 2015. 


\section{INTRODUÇÃO}

A família Bignoniaceae compreende 120 gêneros de ampla distribuição nas regiões tropicais de todo o mundo, especialmente frequentes nos trópicos americanos. São plantas lenhosas, arbustivas ou arbóreas e também trepadeiras (Joly, 1993). No Brasil, plantas dessa família não possuem habitat único, podendo ser encontradas desde a Região Amazônica até o Rio Grande do Sul (Lorenzi \& Matos, 2002).

A coleção de plantas medicinais, aromáticas e condimentares da Embrapa Amazônia Ocidental possui dentre várias espécies o crajiru [Arrabidaea chica (Bonpl.) B. Verl.], também conhecida como crajiru, carajuru, pariri, cipó cruz, coá-pyranga, guajuru, guajuru-piranga, oajuru, ou pyranga (Borrás, 2003), pertencente à família Bignoniaceae, a qual representa uma das 71 espécies vegetais integrantes da Relação Nacional de Plantas Medicinais de Interesse ao Sistema Único de Saúde - RENISUS (Brasil, 2009).

A espécie é de amplo emprego popular para fins terapêuticos, sendo suas folhas usadas para o tratamento de feridas, impigem, enfermidades da pele de diferentes origens, inflamações uterinas e ovarianas, conjuntivite, cólicas intestinais, diarréias sanguinolentas e enterocolites. Também é utilizada como adstringente, antileucêmica, antianêmica, antiinflamatória, antidisentérica, emoliente, antidiabética, cicatrizante e desinfetante. Quimicamente já foram identificadas as seguintes substâncias: ácido anísico, carajurina, ferro assimilável e cianocobalamina, quinonas, flavonoides, triterpenos, cumarinas, taninos, saponinas, carajurina, 3-deoxiantocianidina, bixina e genipina (Estevez, 1976; Gottlieb, 1981; Albuquerque, 1989; Bernal \& Correa, 1989; Schultes \& Raffauf, 1990; Michalak, 1997).

Nos quintais das casas, seja nas cidades, margem dos rios ou mesmo em terra firme, predomina um tipo de crajiru que apresenta folhas estreitas, quando comparado com outros que apresentam folhas mais largas e maior tendência a ser escandente, mesmo sem a presença de mourões. Em função disso convencionou-se denominar os mesmos por tipos, sendo o mais comum o Tipo 1, e assim sucessivamente.

O desenvolvimento vegetal e, em especial, a produção de metabólitos secundários em plantas medicinais é influenciado por diversos fatores ambientais, incluindo condições de solo (GobboNeto \& Lopes, 2007). Nesse sentido, sabe-se que os solos da Amazônia, apresentam, em sua maioria, características de solos ácidos e de baixa fertilidade natural, sendo necessário o uso de alternativas para contornar esse problema, visando uma produção adequada de plantas medicinais. Desta forma, a adubação orgânica deve ser investigada tendo em vista a possibilidade de acréscimo na produção de biomassa e de compostos orgânicos, além da reciclagem desses resíduos nas propriedades rurais e da recuperação das características físicas, químicas e biológicas do solo.

As respostas das plantas medicinais à adubação orgânica e teores de princípios ativos são variáveis e, até o momento, não existe recomendação de fontes e nem de doses de adubos para o cultivo de $A$. chica. Portanto, há a necessidade de pesquisas científicas para definir índices técnicos para esta espécie e, assim, consolidá-los em um sistema de produção.

Portanto, o presente trabalho teve como objetivo avaliar a produção de biomassa aérea, teor e rendimento de extratos nas folhas de crajiru (Arrabidaea chica) em função de adubação orgânica em Manaus, AM.

\section{MATERIAL E MÉTODOS}

O experimento foi conduzido no Setor de Plantas Medicinais da Embrapa Amazônia Ocidental, localizado no Km 29 da AM-010 (ManausItacoatiara) no período de dezembro de 2010 a agosto de 2011.

O solo da área experimental foi caracterizado como Latossolo amarelo distrófico, textura muito argilosa de acordo com Embrapa (2013) declividade de aproximadamente $2 \%$, com índice pluviométrico médio anual de $2.500 \mathrm{~mm}$.

As amostras de solo retiradas na profundidade de 0 a $20 \mathrm{~cm}$ foram encaminhadas ao Laboratório de Análises de Solos e Plantas (LASP) da Embrapa Amazônia Ocidental, para avaliação dos seguintes atributos químicos: $\mathrm{pH}$ em água, fósforo $(P)$, potássio $(K)$, sódio $(\mathrm{Na})$, cálcio $(\mathrm{Ca})$, magnésio $(\mathrm{Mg})$, alumínio $\left(\mathrm{Al}^{3+}\right)$, acidez potencial $(\mathrm{H}+\mathrm{Al})$, matéria orgânica, ferro $(\mathrm{Fe})$, zinco $(\mathrm{Zn})$, manganês $(\mathrm{Mn})$ e cobre $(\mathrm{Cu})$, conforme Embrapa (1999), sendo estes resultados descritos na Tabela 1.

Iniciou-se o preparo da área com a limpeza, sendo realizada uma aração e, em seguida, feita a distribuição da quantidade de $2 \mathrm{t} / \mathrm{ha}$ de calcário dolomítico com PRNT de 95\% com a finalidade de aumentar a saturação de bases para $60 \%$, seguida de duas gradagens para a incorporação do corretivo, cerca de 90 dias antes do plantio.

O experimento foi conduzido em esquema fatorial $5 \times 3$, onde foram utilizadas cinco fontes de adubo orgânico e três morfotipos de crajiru, empregando-se o delineamento em blocos casualizados, com três repetições. Os níveis de fatores foram: Controle (CL) - ausência; Composto 
TABELA 1. Características químicas do solo onde foi realizado o experimento de Arrabidaea chica. Embrapa Amazônia Ocidental, Manaus - AM, 2012.

\begin{tabular}{|c|c|c|c|c|c|c|c|c|c|c|}
\hline & $\mathrm{pH}$ & C & & M.O. & $\mathbf{P}$ & K & $\mathrm{Na}$ & $\mathrm{Ca}$ & $\mathrm{Mg}$ & Al \\
\hline Prof & $\mathrm{H}_{2} \mathrm{O}$ & \multicolumn{3}{|c|}{---------g kg-1------. } & \multicolumn{3}{|c|}{ - } & \multicolumn{3}{|c|}{ - $\mathrm{cmol}_{\mathrm{c}} \mathrm{dm}^{-3}$} \\
\hline $0-20$ & 4,9 & 18,31 & & 41 & 3,0 & 28 & 2,0 & 1,35 & 1,11 & 0,3 \\
\hline $\mathrm{H}+\mathrm{Al}$ & SB & $T$ & $T$ & & v & $M$ & $\mathrm{Fe}$ & $\mathrm{Zn}$ & $M n$ & $\mathrm{Cu}$ \\
\hline \multicolumn{5}{|c|}{ 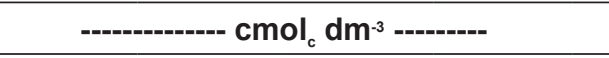 } & \multicolumn{2}{|c|}{ 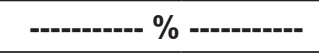 } & \multicolumn{4}{|c|}{ 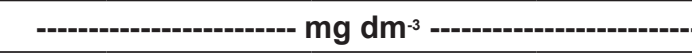 } \\
\hline 4,79 & 2,55 & 2,85 & 7,34 & & 34 & 10,52 & 202 & 1,59 & 4,10 & 0,70 \\
\hline
\end{tabular}

orgânico (CO) - 5,0 kg m²; Esterco de aves (EA) - 3,0 $\mathrm{kg} \mathrm{m}^{-2}$; Casca de guaraná (CG) - 4,0 kg m² e Esterco de gado (EG) - 4,0 $\mathrm{kg} \mathrm{m}^{-2} \mathrm{e}$, os três morfotipos de crajiru sendo estes Morfotipo 1 (MT1), Morfotipo 2 (MT2) e Morfotipo 3 (MT3), onde cada parcela apresentou 16 plantas com quatro na área útil.

Foram utilizadas fontes curtidas de $\mathrm{CO}$, EA, CG e EG, sendo retiradas amostras de $500 \mathrm{~g}$ de cada fonte e enviadas para o Laboratório de Análises de Solos e Plantas da Embrapa Amazônia Ocidental para determinação dos teores de nutrientes (Tabela 2). Essas fontes foram incorporadas ao solo 30 dias antes do plantio.

As mudas de Arrabidaea chica (Bonpl.) B. Verl. foram obtidas por estaquia de 10 matrizes cultivadas no Setor de Plantas Medicinais da Embrapa Amazônia Ocidental, as quais foram identificadas e as exsicatas depositadas no Herbário do Instituto Federal do Amazonas (IFAM) sob os números IFAM 6791 (MT1), IFAM 6792 (MT2) e IFAM 6793 (MT3).

As estacas dos três morfotipos da espécie foram coletadas na porção mediana do ramo, possuindo, em média, $20 \mathrm{~cm}$ de comprimento e 1,0 $\mathrm{cm}$ de diâmetro com cerca de quatro gemas, sendo plantadas em bandejas de poliestireno expandido (72 células) utilizando-se o substrato comercial Bioplant $\AA$, as quais permaneceram em condição de viveiro recebendo irrigação diariamente durante 60 dias.

As mudas foram levadas ao campo aos dois meses de idade, em outubro de 2010, apresentando aproximadamente $40 \mathrm{~cm}$ de altura. Estas foram plantadas em covas de $15 \mathrm{~cm}$ de profundidade, no espaçamento de $1,0 \mathrm{~m} \times 1,0 \mathrm{~m}$ e 2,0 $\mathrm{m}$ entre os blocos, sendo os tratos culturais como o controle de plantas competidoras com capina manual e irrigação realizada de acordo com a necessidade.

Em agosto de 2011, aos 240 dias após o plantio no campo foi feito o corte das plantas da área útil de cada parcela. $\mathrm{O}$ corte foi feito a uma altura de $30 \mathrm{~cm}$ em relação à superfície do solo. Após o corte foi feita a separação das folhas e caules. Posteriormente, foi feita a determinação de massa dessas estruturas em balança analítica.

Para determinação da umidade de folhas e caules, foram utilizadas amostras de aproximadamente $20 \mathrm{~g}$, retiradas de cada parcela, sendo, em seguida, levadas à estufa com ventilação forçada, com temperatura de $65^{\circ} \mathrm{C}$ até atingirem massa constante ( \pm 04 dias).

Determinou-se também a relação da produção de folhas sobre a produção de caules (RF/C).

O resto das folhas foi posto para secar à temperatura ambiente, em galpão coberto, onde após cinco dias as amostras de cada parcela foram acondicionadas em sacos de papel, etiquetados, para posterior determinação do teor de extratos.

As folhas secas foram moídas em moinho industrial do Tipo Willey com malha de $0,5 \mathrm{~mm}$ de abertura e armazenadas em sacos de polietileno

TABELA 2. Teores de nitrogênio $(N)$, fósforo $(P)$, potássio $(K)$, cálcio $(C a)$, magnésio $(M g)$, enxofre $(S)$, boro $(B)$, cobre ( $\mathrm{Cu})$, ferro (Fe), manganês $(\mathrm{Mn})$ e zinco $(\mathrm{Zn})$ das fontes orgânicas: composto orgânico (CO); esterco de aves (EA); casca de guaraná (CG) e esterco de gado (EG). Embrapa Amazônia Ocidental, Manaus - AM, 2012.

\begin{tabular}{|c|c|c|c|c|c|c|c|c|c|c|c|}
\hline \multirow[t]{2}{*}{ Fontes orgânicas } & $\mathrm{N}$ & $\mathrm{P}$ & K & $\mathrm{Ca}$ & $\mathrm{Mg}$ & $S$ & $B$ & $\mathrm{Cu}$ & $\mathrm{Fe}$ & $\mathrm{Mn}$ & $\mathrm{Zn}$ \\
\hline & & \multicolumn{4}{|c|}{$\mathrm{g} \mathrm{kg}^{-1}$} & & & & $\mathrm{mg} \mathrm{kg}^{-1}$ & & \\
\hline $\mathrm{CO}$ & 31,75 & 4,91 & 7,06 & 13,80 & 3,24 & 2,53 & 18,92 & 37,43 & 3944,76 & 167,80 & 154,23 \\
\hline EA & 30,91 & 19,10 & 25,00 & 26,70 & 6,24 & 5,94 & 44,20 & 67,26 & 1024,54 & 332,57 & 532,87 \\
\hline CG & 27,49 & 1,14 & 4,62 & 6,02 & 1,65 & 2,28 & 22,03 & 24,27 & 3060,23 & 63,22 & 165,36 \\
\hline EG & 26,05 & 6,57 & 6,71 & 8,63 & 5,04 & 6,59 & 17,40 & 98,35 & 3874,63 & 203,75 & 245,13 \\
\hline
\end{tabular}

Rev. Bras. PI. Med., Campinas, v.17, n.3, p.444-453, 2015. 
isentos de luz e ar. $\mathrm{O}$ pó das folhas de $A$. chica foi encaminhado ao Laboratório de Estruturas de Superfície de Microrganismos do Instituto de Microbiologia Paulo de Góes da Universidade do Rio de Janeiro para análises fitoquímicas. Os $10 \mathrm{~g}$ das folhas secas e moídas (massa total das amostras de cada parcela) foram extraídas exaustivamente por maceração sob agitação manual em hexano $(100 \mathrm{~mL})$, à temperatura ambiente, na ausência de luminosidade, e, após uma semana, o extrato foi filtrado em papel de filtro.

Os extratos foram concentrados em um evaporador rotativo da marca BUCHI sob pressão reduzida à temperatura de $30^{\circ} \mathrm{C}$, eliminando todo o hexano, sendo o resíduo do extrato hexânico designado EHAc (Extrato Hexânico de Arrabidaea chica), obtendo-se assim o teor de extrato para cada amostra.

O rendimento de extrato foi calculado pela fórmula:

Teor de extrato $=($ Massa do extrato/Massa da amostra total $) \times 100$

Rendimento de extrato $=(\%$ extrato $x$ massa seca total das folhas $) / 100$

As médias foram submetidas à Análise de Variância pelo Teste $\mathrm{F}$ e, em caso de efeito significativo para tratamentos, realizou-se o Teste de Tukey, ao nível de $5 \%$ de probabilidade para comparação das médias. As análises foram feitas com auxílio do programa estatístico SAEG 9.1.

\section{RESULTADOS E DISCUSSÃO}

Os dados climáticos observados durante o período de condução do experimento em campo encontram-se na Figura 1. Pode-se notar que a temperatura média mensal nesse período esteve próxima de $26^{\circ} \mathrm{C}$ com precipitação média de aproximadamente $252 \mathrm{~mm}$ e insolação de 124 horas.

Biomassa vegetal

$\mathrm{Na}$ Tabela 3 estão apresentados os resultados da análise de variância dos componentes de produção de $A$. chica, provenientes da aplicação de diferentes fontes orgânicas. Tanto o fator morfotipos de crajiru como o fator fontes de adubação orgânica foram significativos pelo Teste $F(p<0,05)$ para todas as variáveis de produção: massa seca de folhas, massa seca de caules, relação folha/caule, teor e rendimento de extratos, assim como a interação entre eles.

As plantas cultivadas com aplicação de EA e EG apresentaram maiores médias para a variável massa seca de folhas com diferenças significativas entre os demais tratamentos utilizados (Figura 2). Ainda para MSF, ao comparar-se a produção de folhas entre os morfotipos de crajiru, verificou-se maior quantidade de matéria seca nos morfotipos 2 e 3 , não havendo diferença significativa entre os dois, embora as médias do MT3 tenham apresentado valores superiores.

Já em relação às fontes utilizadas

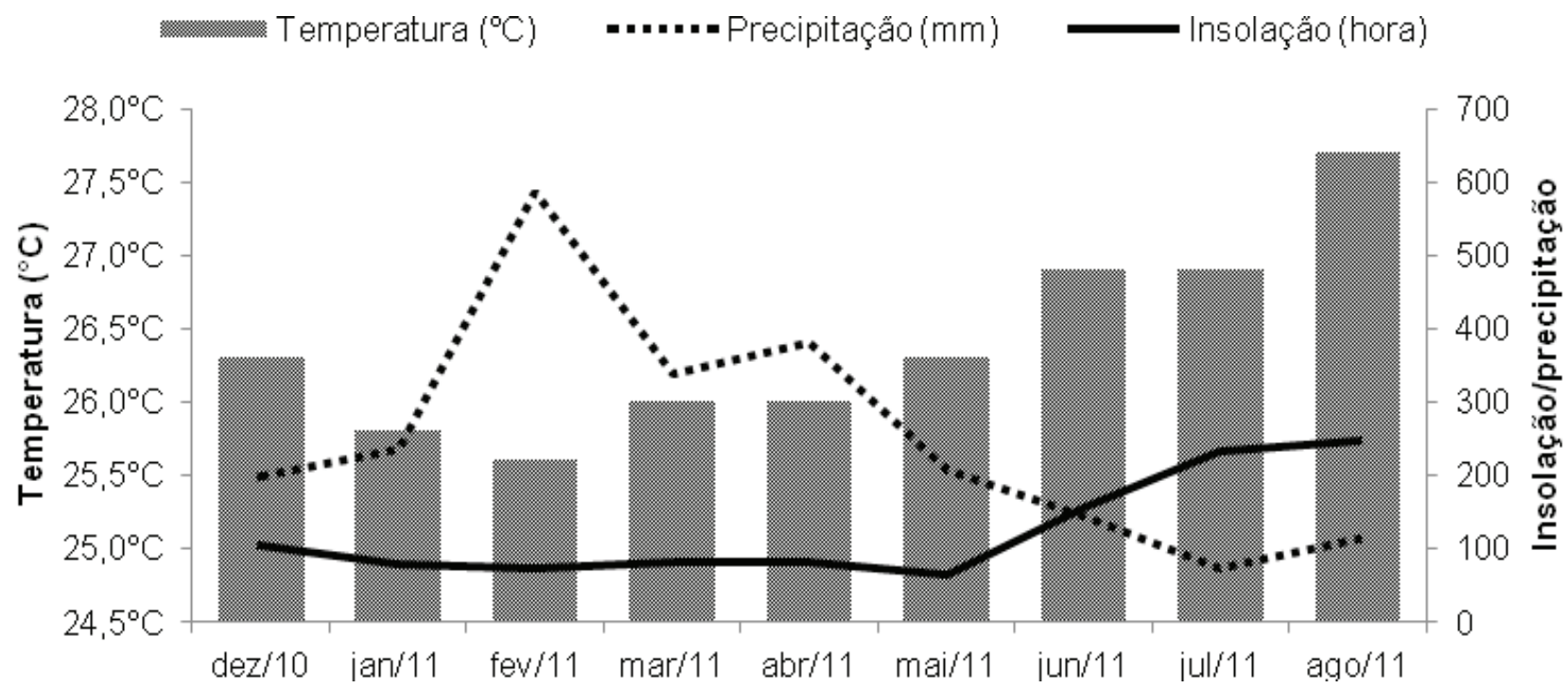

FIGURA 1. Dados de temperatura, precipitação e insolação médias mensais durante a condução de plantas de A. chica para a produção de biomassa aérea, teor e rendimento de extratos das folhas em função da adubação orgânica. Embrapa Amazônia Ocidental, Manaus-AM, 2012. 
TABELA 3. Quadrados médios das variáveis: massa seca de folhas (MSF) e caules (MSC), relação folha caule (R F/C), teor (TE) e rendimento de extratos (RE) de folhas de três morfotipos de crajiru em função da adubação orgânica. Manaus - AM. 2012.

\begin{tabular}{ccccccc}
\hline F. V & GL & MSF & MSC & RF/C & TE & RE \\
Adub. & 4 & $1470,11^{* *}$ & $4825,13^{* *}$ & $0,09^{* *}$ & $6,81^{* *}$ & $23,78^{* *}$ \\
Morf. & 2 & $70725,22^{* *}$ & $152539,37^{* *}$ & $0,61^{* *}$ & $15,60^{* *}$ & $175,95^{* *}$ \\
Adub. X Morf. & 8 & $621,99^{* *}$ & $4109,22^{* *}$ & $0,06^{* *}$ & $3,18^{* *}$ & $11,84^{* *}$ \\
\hline Tratamentos & 14 & $10879,06^{* *}$ & $25518,07^{* *}$ & $0,15^{* *}$ & $5,99^{* *}$ & $38,71^{* *}$ \\
\hline Blocos & 2 & $550,48^{*}$ & 42,39 & 0,01 ns & 0,03 & 1,83 \\
\hline Resíduo & 28 & 147,04 & 160,33 & 0,01 & 0,35 & 1,35 \\
CV $(\%)$ & & 11,56 & 9,73 & 8,54 & 12,46 & 23,27 \\
\hline
\end{tabular}

** - significativo a nível de $1 \%$ de probabilidade $(\mathrm{p}<0,01)$ pelo Teste $\mathrm{F}$.

* - significativo a nível de $5 \%$ de probabilidade $(0,01<p<0,05)$ pelo Teste $F$. ns - não significativo

constatou-se que para o MT1 as médias não diferiram significativamente entre si, embora o EA tenha apresentado maior valor (35,83 $\left.\mathrm{g}^{\text {planta-1 }}\right)^{-}$, enquanto o EG teve menor valor (14,85 $\left.\mathrm{g}_{\text {planta-1 }}{ }^{-1}\right)$. No entanto, os adubos EA, EG e CG contribuíram mais significativamente para as plantas do MT2 e MT3, onde as maiores médias nessa variável foram observadas para EA, com $162,71 \mathrm{~g}$ planta-1 $^{-1}$

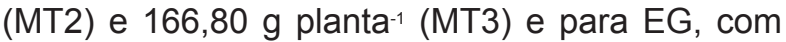
146,28 g planta-1 $^{-1}$ MT2) e 171,37 g planta-1 $^{-1}$ (MT3), respectivamente, embora não tenha havido diferença significativas entre os mesmos.

As médias de massa seca de caules (Figura 3) mostraram que houve significância estatística entre as fontes de adubação orgânica empregadas, verificando-se maior produção nos tratamentos que receberam adição de $\mathrm{EA}$ e $\mathrm{CO}$, sendo que o MT3 sobressaiu-se aos demais para esta variável, seguido do MT2 e, finalmente, do MT1.

Esse fator pode ser explicado pela arquitetura diferenciada entre os referidos morfotipos, onde os MT2 e MT3 apresentam quantidades consideráveis de ramificações, enquanto o MT1 exibe características de uma planta com porte mais ereto e com menos número de ramos, enquanto o porte dos outros dois é mais escandente, tendendo a uma forma semelhante a uma touceira, também contribuindo para isso o tamanho das folhas que no MT1 são mais finas e menores.

Contudo, ainda para a variável massa seca

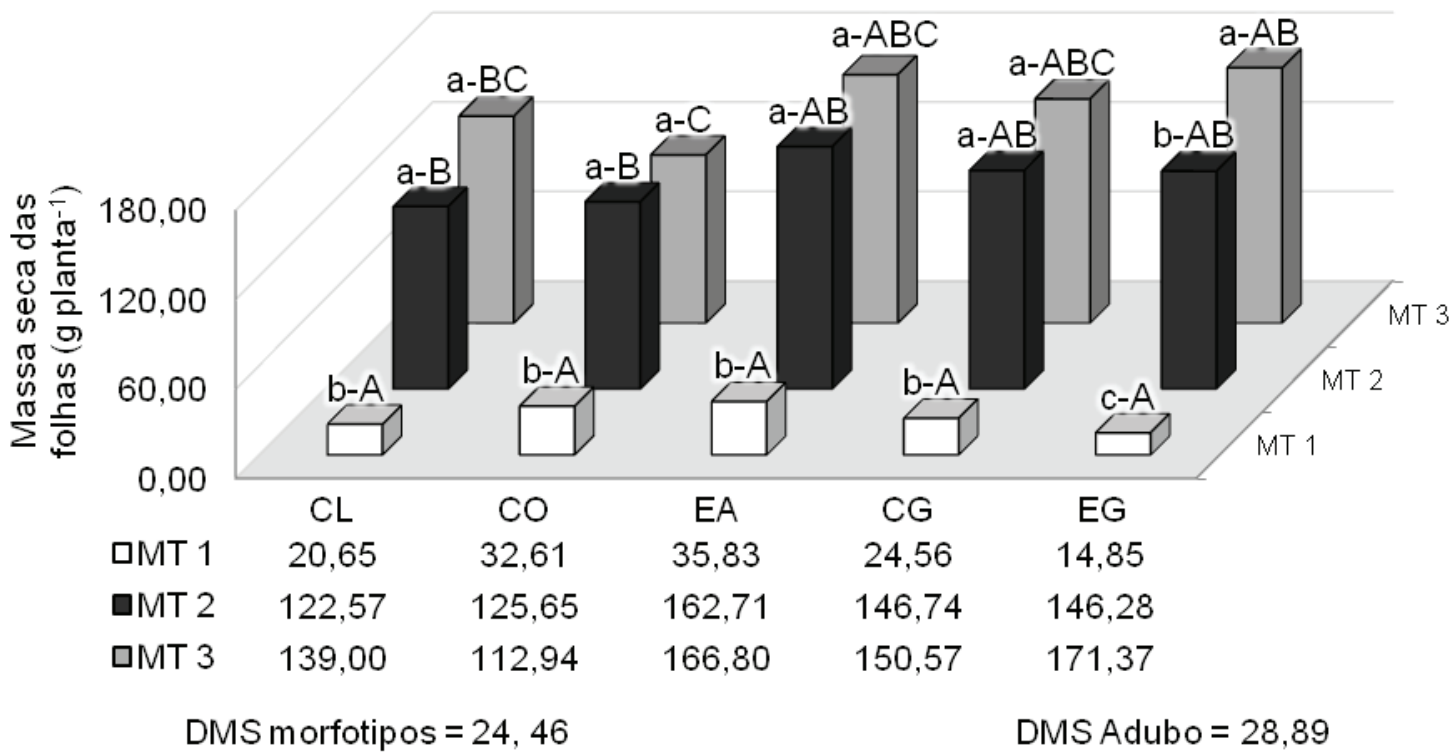

FIGURA 2. Massa seca de folhas de três morfotipos de A. chica: morfotipo 1 (MT1); morfotipo 2 (MT2) e morfotipo 3 (MT3), cultivadas sob condições de campo, em função das fontes de adubo orgânico: controle (CL); composto orgânico (CO); esterco de aves (EA); casca de guaraná (CG) e esterco de gado (EG) em Manaus, AM. 2010-11. Médias seguidas de mesma letra na coluna (minúscula) comparam entre si os morfotipos enquanto as letras na linha (maiúsculas) comparam entre si os adubos, não diferindo entre si pelo Teste de Tukey $(p<0,05)$. 
de caules, averiguou-se que não houve diferença significativa entre os adubos utilizados para o MT1, todavia, tanto para o MT2 como para o MT3 houve diferenças estatísticas em relação às fontes orgânicas, sendo a fonte CG para o MT2 superior em média às demais fontes orgânicas, com 174,91 g/planta, no entanto, não diferindo estatisticamente do EA (149,59 g/planta), EG (137,82 g/planta) e do CO (122,07 g/planta). Em relação ao MT3, o EA foi o que alcançou melhor resultado (309,76 g/planta), apresentando este, média mais elevada que todas as demais interações.

Entre os morfotipos estudados, os 1 e 2 não apresentaram diferenças estatísticas exceto para o adubo orgânico CG, onde estes se diferenciaram ao do MT3, demonstrando a diferença nas respostas aos tipos de adubos orgânicos entre os morfotipos.

Para a relação folha/caule não houve diferença estatística entre o MT1 e MT2 quanto aos adubos orgânicos avaliados, com exceção para a CG em que a relação folha/caule foi maior para o MT1. No MT1 e MT2 houve maior absorção de nutrientes disponibilizados, ou seja, a capacidade de conversão em biomassa foliar.

Ainda em relação a essa variável, foi constatado que o MT3, em todos os tratamentos, independente da fonte e mesmo da ausência delas, houve relativamente maior queda das folhas no campo, o que contribuiu para os menores valores encontrados de relação folha/caule (Figura 4).
De acordo com o resultado da interação entre as fontes de adubação orgânica e os morfotipos de $A$. chica (Figura 5 ), a fonte que mais se adequou ao MT1 foi EG $(1,19)$, no entanto, sem diferir estatisticamente das demais fontes. Já para o MT2 o tratamento CL mostrou uma média maior $(1,22)$ que as das outras fontes de adubação orgânica, contudo, não houve diferença estatística entre as fontes exceto para a CG. Para o MT3 as fontes CG $(0,19)$ e $E G(0,90)$ não diferiram entre si pelo teste de Tukey e apresentaram médias superiores às demais.

Estes resultados demonstram que mesmo dentro da espécie, existe uma resposta diferencial quanto ao aproveitamento dos nutrientes fornecidos pelas diversas fontes orgânicas, o que possivelmente envolve parâmetros genéticos de absorção e utilização dos mesmos, para cada morfotipo.

Muitos trabalhos têm mostrado a importância da composição química dos solos no desenvolvimento de plantas medicinais, testando diferentes tipos e níveis de adubação (Ming, 1998; Ferreira, 2004; Montanari et al., 2004; Pereira et al., 2006; Rosal et al., 2009). Rosal et al. (2011), por exemplo, estudando o efeito de diferentes fontes de adubos orgânicos na produção de biomassa de boldo pequeno (Plectranthus neochilus), observaram que as plantas adubadas com esterco avícola promoveram maior produção de biomassa e rendimento de óleo essencial.

Ainda com a finalidade de verificar a

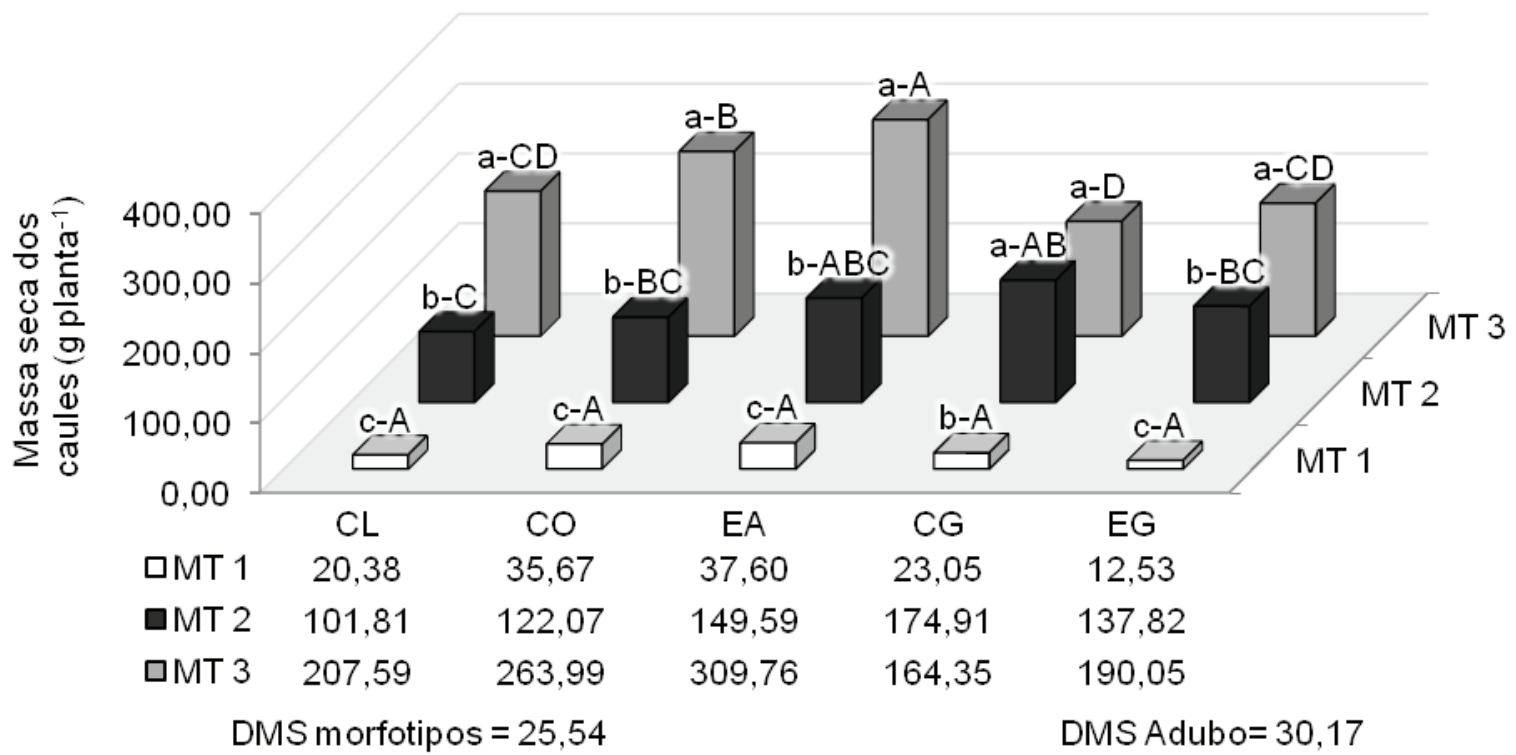

FIGURA 3. Massa seca de caules de três morfotipos de A. chica: morfotipo 1 (MT1); morfotipo 2 (MT2) e morfotipo 3 (MT3), cultivadas sob condições de campo, em função das fontes de adubo orgânico: controle (CL); composto orgânico (CO); esterco de aves (EA); casca de guaraná (CG) e esterco de gado (EG) em Manaus, AM. 2012. Médias seguidas de mesma letra na coluna (minúscula) comparam entre si os morfotipos enquanto as letras na linha (maiúsculas) comparam entre si os adubos, não diferindo entre si pelo Teste de Tukey $(p<0,05)$. 

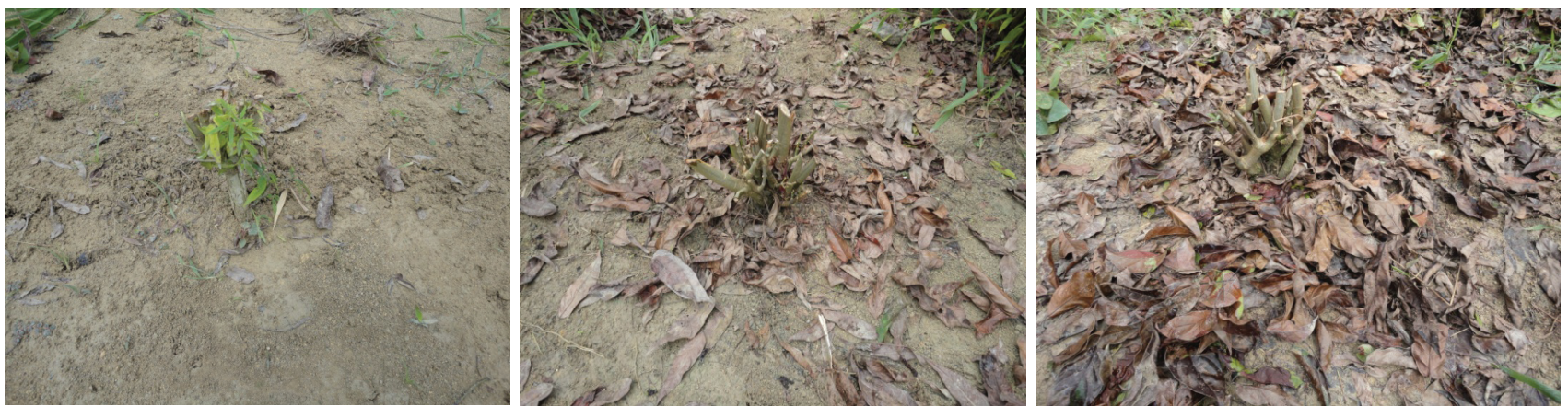

FIGURA 4. Plantas dos morfotipos MT1 (a); MT2 (b); e MT3 (c) de A. chica cultivados com diferentes fontes de adubo orgânico, após o corte. Manaus, AM - 2011.

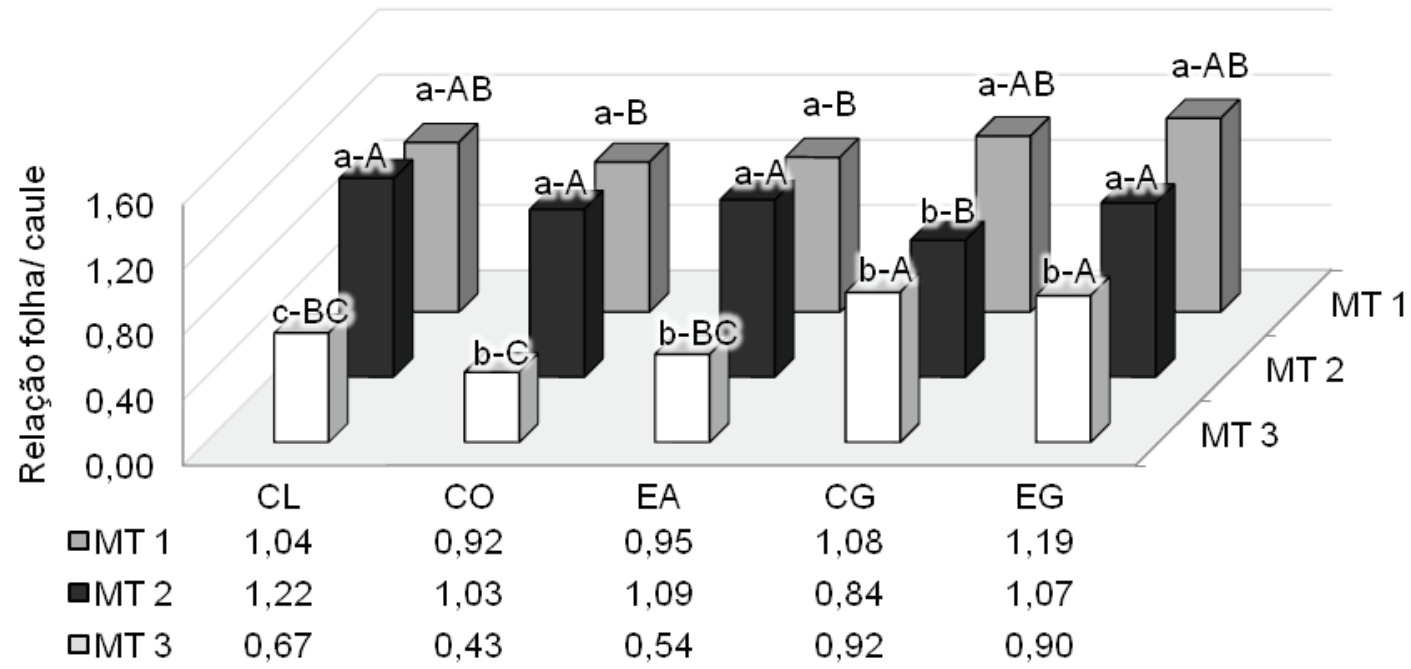

DMS morfotipos $=0,15$

DMS Adubo $=0,18$

FIGURA 5. Relação folha/caule de três morfotipos de A. chica: morfotipo 1 (MT1); morfotipo 2 (MT2) e morfotipo 3 (MT3), cultivadas sob condições de campo, em função das fontes de adubo orgânico: controle (CL); composto orgânico (CO); esterco de aves (EA); casca de guaraná (CG) e esterco de gado (EG) em Manaus, AM. 2010-11. Médias seguidas de mesma letra na coluna (minúscula) comparam entre si os morfotipos enquanto as letras na linha (maiúsculas) comparam entre si os adubos, não diferindo entre si pelo Teste de Tukey $(p<0,05)$.

influência de fontes de adubo orgânico sobre o desenvolvimento de plantas medicinais, Costa et al. (2008a) constataram que para capim-limão (Cymbopogon citratus), o esterco avícola também proporcionou melhores resultados de produção de biomassa seca total. Melhor desenvolvimento de plantas adubadas com esterco avícola também foram encontrados por Costa et al. (2008b), Maia et al. (2008), Corrêa et al. (2010).

Portanto, maiores resultados de biomassa devem ser atribuídos à maior concentração de nutrientes e à maior disponibilidade ao longo do ciclo ou avaliação do experimento.

\section{Teor e rendimento de extratos}

$\mathrm{Na}$ figura 6, observa-se que na CG e no EG não houve diferença entre os morfotipos avaliados quanto ao teor de extrato. Mas no CO e CL o MT1 e MT2 não diferiram entre si e proporcionaram uma maior porcentagem de extrato. No EA o MT2 foi o morfotipo que produziu maior teor de extrato.

Características genéticas dos morfotipos de crajiru podem ter influenciado a resposta do teor de extrato hexânico para as diferentes fontes de adubação orgânica. O teor de extrato relativamente superior apresentado pelo MT2 em resposta ao EA, pode ser consequência do investimento natural em folhas e caule quando comparado aos demais morfotipos, logo que a produção caulinar e foliar do MT1 e altamente proporcional, porém, sua folha é menor e menos espessa que os demais morfotipos, consequentemente pode haver uma quantidade menor de compostos extraíveis. Apesar da espessura de sua folha ser semelhante ao MT2, 
há um investimento maior do MT3 na parte caulinar quando comparado com o seu investimento em folhas. Em decorrência disto, parte dos compostos que poderiam estar presentes na folha, podem estar em maior concentração no caule da planta.

O EA assim como para grande parte das variáveis analisadas anteriormente, foi o que proporcionou maior teor de extrato. Este resultado pode estar relacionado ao fato da produção de compostos extraídos pelo hexano, serem possivelmente dependentes da qualidade nutricional da planta, uma vez que maiores concentrações de nutrientes foram encontrados no $E A$, o que proporcionaria maior disponibilidade de nutrientes à cultura, que aliado a um possível fator genético de absorção e aproveitamento dos nutrientes tenha promovido estes resultados.

Portanto, os resultados da interação entre fontes de adubação orgânica e morfotipos no rendimento de extratos de $A$. chica expostos na Figura 7 revelaram que para o MT1 não houve diferença significativa entre os adubos utilizados.

Já para o MT2, o EA foi o adubo que obteve médias estatísticas superiores aos demais (13,86 g/ planta). Para o MT3 os adubos EA, CG e EG não diferiram estatisticamente entre si e proporcionaram maior rendimento de extrato.

Entre os morfotipos estudados, foi possível verificar que o MT2, atingiu melhores médias em relação aos morfotipos 1 e 3, principalmente quando este foi conduzido sob o tratamento EA, o qual se revelou como a melhor fonte de adubação orgânica para a obtenção de extratos de crajiru.

Até o momento não consta na literatura trabalhos referentes à influência da adubação no teor e rendimento de extratos. No entanto, considerando que a nutrição é um dos fatores que pode interferir na composição química e na quantidade de princípios ativos das plantas, é possível encontrar diversos estudos que relacionam o rendimento de óleo essencial à adubação.

Maiores teores de óleo essencial foram encontrados em arnica (Lychnophora pinaster) submetida à adubação orgânica com e sem calagem e à adubação mista sem calagem, em relação à adubação mineral (Oliveira Júnior et al., 2006).

Costa et al. (2008 b) estudando o efeito da adubação orgânica na produção de biomassa e óleo essencial em elixir paregórico (Ocimum selloi) verificaram que houve influência positiva do esterco avícola no acúmulo de massa seca, rendimento e composição química de óleo essencial.

Os fatores que afetaram a produção de biomassa seca da parte aérea afetaram também o teor e rendimento de extrato de $A$. chica, como observado por diversos autores que encontraram maiores rendimentos de óleos essenciais com o aumento dos níveis de nutrientes proporcionados pela adubação orgânica (Ferreira et al., 2004; Souza et al., 2007; Sales et al., 2009; Chagas et al., 2011). Contudo, as fontes de adubo orgânico promoveram maior produção de

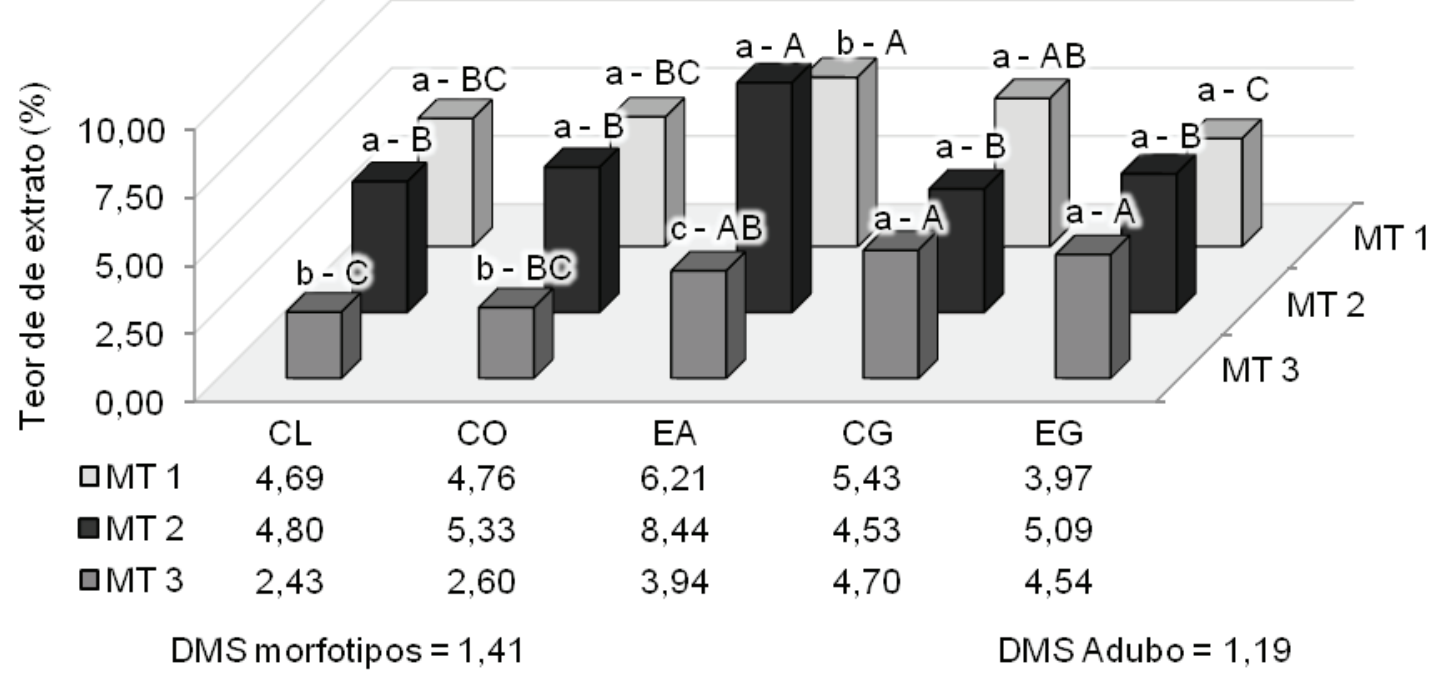

FIGURA 6. Teor de extrato (\%) em folhas de três morfotipos de A. chica: morfotipo 1 (MT1); morfotipo 2 (MT2) e morfotipo 3 (MT3), cultivadas sob condições de campo, em função das fontes de adubo orgânico: controle (CL); composto orgânico (CO); esterco de aves (EA); casca de guaraná (CG) e esterco de gado (EG) em Manaus, AM. 2010-11. Médias seguidas de mesma letra na coluna (minúscula) comparam entre si os morfotipos enquanto as letras na linha (maiúsculas) comparam entre si os adubos, não diferindo entre si pelo Teste de Tukey ( $p<0,05)$. 


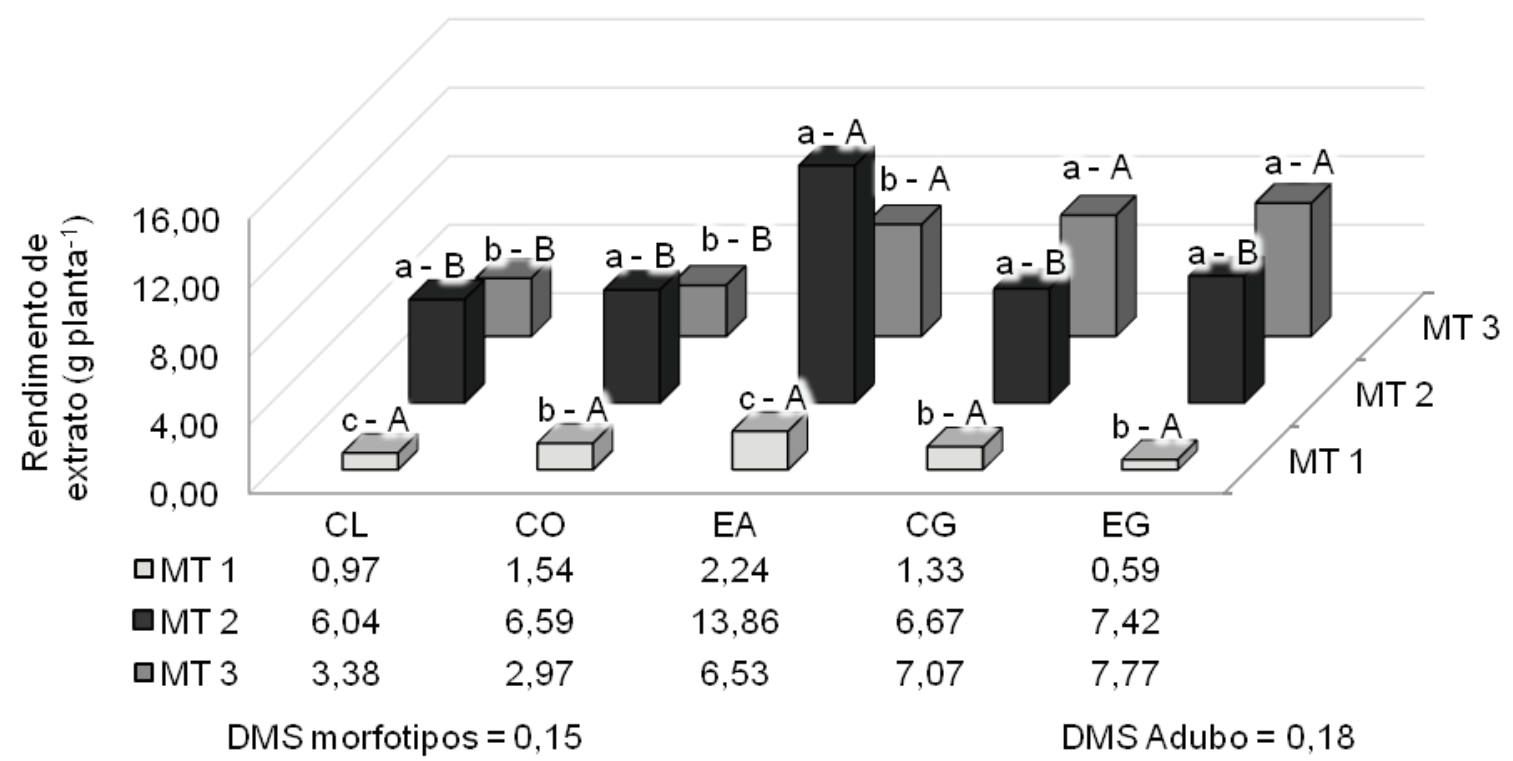

FIGURA 7. Rendimento de extrato (g/planta) em folhas de três morfotipos de A. chica: morfotipo 1 (MT1); morfotipo 2 (MT2) e morfotipo 3 (MT3), cultivadas sob condições de campo, em função das fontes de adubo orgânico: controle (CL); composto orgânico (CO); esterco de aves (EA); casca de guaraná (CG) e esterco de gado (EG) em Manaus, AM. 2010-11. Médias seguidas de mesma letra na coluna (minúscula) comparam entre si os morfotipos enquanto as letras na linha (maiúsculas) comparam entre si os adubos, não diferindo entre si pelo Teste de Tukey $(p<0,05)$.

biomassa aérea e rendimento de extrato de $A$. chica, para os morfotipos 2 e 3 em relação ao tratamento controle, sendo o esterco de aves, de modo geral, o adubo que proporcionou maior produção de biomassa aérea, maior teor e rendimento de extrato para os morfotipos estudados.

\section{AGRADECIMENTOS}

Os autores agradecem à CAPES, CNPq e Embrapa Amazônia Ocidental pela concessão de bolsas de estudos e apoio financeiro.

\section{REFERÊNCIAS}

ALBUQUERQUE, J.M. de. Plantas medicinais de uso popular. Brasília: ABEAS/MEC, 1989. 96p.

BERNAL, H.Y.; CORREA, J.E. Espécies vegetais promissoras de los países del convenio Andrés Bello. Bogotá: Secretaria Ejecutiva del convenio André Bello, 1989. v.2, p.169-72.

BORRÁS, M.R.L. Plantas da Amazônia: medicinais ou mágicas? Plantas comercializadas no mercado municipal Adolpho Lisboa. Manaus: Valer/Governo do Estado do Amazonas, 2003. 321p.

BRASIL. Relação Nacional de Plantas Medicinais de Interesse ao Sistema Único de Saúde. In: Brasil. Ministério da Saúde. SUS - RENISUS. Diário Oficial da União. Brasília. 2009.

CHAGAS, J.H.; PINTO, J.E.B.P.; BERTOLUCCI, S.K.V.; SANTOS, F.M.; BOTREL, P.P.; PINTO, L.B.B. Produção da hortelã-japonesa em função da adubação orgânica no plantio e em cobertura. Horticultura Brasileira. Brasília. v. 29, n.3, p. 412-417, 2011.

CORRÊA, R.M.; PINTO, J.E.B.P.; REIS, E.S.; COSTA, L.C.B.; ALVES, P.B.; NICULAN, E.S.; BRANT, R.S. Adubação orgânica na produção de biomassa de plantas, teor e qualidade de óleo essencial de orégano (Origanum vulgare L.) em cultivo protegido. Revista Brasileira de Plantas Medicinais, Botucatu, v.12, n.1, p.80-89, 2010.

COSTA, L.C.B.; ROSAL, L.F.; PINTO, J.E.B.P.; BERTOLUCCI, S.K.V. Efeito da adubação química e orgânica na produção de biomassa e óleo essencial em capim-limão [Cymbopogon citratus (DC.) Stapf.]. Revista Brasileira de Plantas Medicinais, Botucatu, v.10, n.1, p.16-20, 2008a.

COSTA, L.C.B.; PINTO, J.E.B.P.; CASTRO, E.M.; BERTOLUCCI, S.K.V.; CORREAA, R. M.; REIS, E.S.; ALVES, P.B.; NICULAU, E.S. Tipos e doses de adubação orgânica no crescimento, no rendimento e na composição química do óleo essencial de elixir paregórico. Revista Ciência Rural, v.38, n.8, p. 21732180, 2008b.

EMBRAPA. Manual de análises químicas de solos, plantas e fertilizantes. Brasília: Embrapa Solos/ Embrapa Informática Agropecuária/Embrapa Comunicação para Transferência de Tecnologia, 1999. 370p.

EMBRAPA. Sistema brasileiro de classificação de solos. Brasília: Embrapa, 2013. 353p.

ESTEVEZ, A. Resultados de la actividad antitumoral y tóxica del principio activo de La Petiveria alliacea. Revista Cubana de Farmacia, v.10, n.1, p.23-26, 1976. FERREIRA, M.M.; MOTA, M.B.; PINTO, J.E.B.P.; 
CASTRO, E.M. Crescimento e alocação de biomassa de plantas de vinca (Catharanthus roseus (L.) G. Don) em função da adubação orgânica e época de colheita. Revista Brasileira de Plantas Medicinais, v.6, n.2, p.72-6, 2004.

GOBBO-NETO, L.; LOPES, N.P. Plantas medicinais: fatores de influência no conteúdo de metabólitos secundários. Química Nova, v.30, n.2, p.374-381, 2007.

GOTTLIEB, O. New and underutilized plants in Americas: solution to problems of inventory throught sistematics. Interciência, v.6, n.1, p.22-29, 1981.

JOLY, A.B. Botânica: introdução à taxonomia vegetal. São Paulo: Editora Nacional, 1993. 776p.

LORENZI, H.; MATOS, F.J.A. Plantas medicinais no Brasil: nativas e exóticas. Nova Odessa: Instituto Plantarum, 2002. 512p.

MAIA, S.S.S; PINTO, J.E.B.P.; SILVA, F.N.; OLIVEIRA, C. Influência da adubação orgânica e mineral no cultivo do bamburral (Hyptis suaveolens (L.) Poit.) (Lamiaceae). Revista Brasileira de Ciências Agrárias, v.3, n.4, p.327-331, 2008.

MICHALAK, E. Apontamentos fitoterápicos da Irmã Eva Michalak. Florianópolis: EPAGRI, 1997. 94p.

MING, L.C. Adubação orgânica no cultivo de Lippia alba (Mill) N.E.Br.- Verbenaceae. In: Ming, L.C. (Coord.). Plantas medicinais, aromáticas e condimentares: avanços na pesquisa agronômica. Botucatu: UNESP, 1998. v.1, p.165-192.

MONTANARI, R.M.; SOUZA, L.A.; LEITE, M.N.; COELHO, A.D.F.; VICCINI, L.F.; STEFANINI, M.B. Plasticidade fenotípica da morfologia externa de Lippia alba (Mill.) N.E.Br. ex Britt. e Wilson (Verbenaceae) em resposta a níveis de luminosidade e adubação. Revista Brasileira de Plantas
Medicinais, v.6, n.3, p.96-101, 2004.

OLIVEIRA JÚNIOR, A.C.; FAQUIN, V.; PINTO, J.E.B.P. Efeitos de calagem e adubação crescimento e nutrição de arnica. Horticultura Brasileira, v.24, n.3, p. 347351, 2006

PEREIRA, E.B.C.; PEREIRA, A.V.; SILVA, D.B.; VIEIRA, R.F. Seedling growth of mamacadela (Brosimum gaudichaudii Trec.) on six different substrates. Revista Brasileira de Plantas Medicinais, v.8, n esp., p.190-192, 2006.

ROSAL, L.F.; PINTO, J.B.P.; BERTOLUCCI, S.V.; BRANT, R.S.; NICULAU, E.S.; ALVES, P. B. Produção vegetal e de óleo essencial de boldo pequeno em função de fontes de adubos orgânicos. Revista Ceres, v. 58, n.5, p.670-678, 2011.

ROSAL, L.F., PINTO, J.E.B.P.; BRANT, R.S. Produção de biomassa e óleo essencial de Plectranthus neochilus Schlechter cultivado no campo sob níveis crescentes de adubo orgânico. Pesquisa Aplicada e Agrotecnologia, v.2, n.2, p.39-44, 2009.

SALES, J.F.; PINTO, J.E.B.P.; BOTREL, P.P.; SILVA, F.G.; CORREA, R.M.; CARVALHO, J.G. Acúmulo de massa, teor foliar de nutrientes e rendimento de óleo essencial de hortelã-do-campo (Hyptis marrubioides Epl.) cultivado sob adubação orgânica. Bioscience Journal, v.25, n.1, p.60-68, 2009.

SCHULTES, R.E.; RAFFAUF, R.F. The healing forest. Medicinal and toxic plants of the northwest amazonia. Portland: Dioscorides Press, 1990. 483p.

SOUZA, M.A.A.; ARAÚJO, O.J.L.; FERREIRA, M.A.; STARK, E.M.L.M.; FERNANDES, M. S.; SOUZA, S.R. Produção de biomassa e óleo essencial de hortelã em hidroponia em função de nitrogênio e fósforo. Horticultura Brasileira, v.25, n.1, p.41-48, 2007. 